\title{
KESANTUNAN LINGUISTIK DALAM LAKUAN PENOLAKAN ORANG MELAYU, DALAM KONTEKS UNDANGAN PERKAHWINAN
}

\author{
RADHIAH ISMAIL* DAN ROSWATI ABDUL RASHID
} Jabatan Bahasa dan Komunikasi, Pusat Pendidikan Asas dan Lanjutan, Universiti Malaysia Terengganu, 21030,
Kuala Nerus, Terengganu, Malaysia

*Pengarang koresponden: radhiah@umt.edu.my

Submitted final draft: 4 July $2020 \quad$ Accepted: 28 August $2020 \quad$ http://doi.org/10.46754/jbsd.2020.09.007

\begin{abstract}
Abstrak: Penolakan merupakan lakuan linguistik yang sukar untuk dilaksanakan dan berpotensi untuk mencetuskan konflik. Bagi menghindar konflik dan mengurangkan kemungkinan menjatuhkan air muka pendengar, penutur akan menggunakan pelbagai strategi kesantunan dalam pengungkapannya. Penulisan ini bertujuan untuk memerihalkan strategi-strategi kesantunan linguistik yang digunakan oleh orang Melayu dalam lakuan bahasa penolakan terhadap undangan ke majlis perkahwinan. Majlis perkahwinan dipilih sebagai konteks kajian kerana ia merupakan salah satu peristiwa penting dan bersejarah dalam kehidupan seseorang dan menghadirinya merupakan satu tuntutan agama. Seramai 40 orang responden Melayu terlibat dalam kajian ini. Ujian Melengkapkan Wacana atau DCT (Discourse Completion Test) merupakan instrument telah digunakan untuk mengumpul data. Data dianalisis berdasarkan model penolakan Beebe, et al. Dapatan menunjukkan majoriti responden menggunakan strategi tidak langsung untuk mengungkapkan penolakan. Strategi "mengemukakan alasan" dan "memohon maaf" telah dikenal pasti sebagai dua strategi yang paling kerap digunakan oleh responden. Dari aspek struktur penolakan pula, kebanyakkan responden memulakan penolakan dengan strategi "memohon maaf" diikuti oleh strategi-strategi yang lain. Kesimpulannnya, adab dan kesantunan berbahasa masih utuh diamalkan oleh masyarakat Melayu ketika berkomunikasi. Dapatan kajian ini diharapkan dapat dijadikan panduan untuk melancarkan dan meningkatkan keberkesanan komunikasi dalam kalangan masyarakat terutama yang melibatkan lakuan bahasa penolakan.
\end{abstract}

Kata kunci: Pragmatik, lakuan bahasa, penolakan, kesantunan bahasa, kesantunan linguistic

\section{Lingustic Politeness in Malay Refusals, in the Context of Wedding Invitations}

Abstract: Refusal is a linguistic act that is difficult to implement and has the potential to provoke conflict. To avoid conflict and reduce the likelihood of offending the listener, the speaker will use a variety of politeness strategies in his expressions. This article aims to describe the linguistic politeness strategies used by the Malays in the speech act of refusal of wedding invitations. A wedding ceremony was chosen as the context of the study because it is one of the important and historical events in one's life and attending it is a religious demand. A total of 40 Malay respondents participated in this study. Discourse Completion Test or DCT was the instrument used to collect data. Data were analyzed based on Beebe et al. refusal model. The findings indicate that most respondents use indirect strategies to express refusal. The "excuse" and "statement of regret" strategies have been identified as the two most frequently used strategies by respondents. From the aspect of the refusal structure, most respondents started 
the refusals with a "statement of regret" strategy followed by other strategies. In conclusion, manners and politeness are still widely practiced by the Malays in communication. It is hoped that the findings of this study can be used as a guide to enhance and improve the effectiveness of communication in society, especially those involving the speech act of refusal.

Keywords: Pragmatics, speech act, refusal, language politeness, linguistic politeness

\section{Pengenalan}

Penolakan merupakan lakuan linguistik yang sukar untuk dilaksanakan dan berpotensi untuk mencetuskan konflik. Menurut Brown dan Levinson (1978), penolakan ialah lakuan bahasa yang boleh mengancam air muka. Ini kerana penolakan bermaksud enggan, tidak sudi, tidak mahu atau tidak bersetuju, yang boleh mendatangkan kesan kehampaan dan tersinggung di pihak pendengar atau orang yang dilawan bercakap. Namun menurut Beebe et. al. (1990), selain pendengar, air muka penutur juga turut terancam bila mana mereka terpaksa menebalkan muka untuk mengungkapkan sesuatu yang akan mengecewakan pihak pendengar. Selain itu, Beebe et al. (1990) juga menyifatkan penolakan sebagai punca konflik kerana sifatnya yang kompleks, iaitu jika diujar secara beralas maksudnya mungkin terlindung, jika dilontar secara bebas hati orang lain pula mungkin tersinggung. Bagi menghindar konflik dan mengurangkan kemungkinan menjatuhkan air muka pendengar, penutur akan menggunakan pelbagai strategi kesantunan untuk mengungkapkan penolakan. Menurut Brown dan Levinson (1987), penggunaan pelbagai strategi kesantunan adalah disebabkan oleh kecenderungan penutur untuk melindungi air muka pendengar dan air mukanya sendiri dalam komunikasi mereka sehari-hari. Menurut mereka lagi, dari satu segi, strategi-strategi tersebut berfungsi sebagai alat yang melemahkan lakuan bahasa yang mengancam air muka. Dari segi yang lain pula ia berperanan sebagai lakuan yang memelihara air muka. Dengan menggunakan strategistrategi kesantunan tertentu, penutur boleh menyampaikan mesej dengan yakin tanpa perlu menanggung risiko menjatuhkan air muka pihak lain.

Dalam konteks undangan ke majlis perkahwinan, penolakan bukanlah suatu tindakan yang mudah untuk dilaksanakan bahkan berpotensi mengundang konflik. Majlis perkahwinan merupakan salah satu peristiwa penting dan bersejarah dalam kehidupan seseorang. Kehadiran mereka yang diundang ke majlis perkahwinan amat dialu-alukan bagi memeriahkan majlis dan meraikan pengantin. Selain diundang ke jamuan makan, sebahagian tetamu seperti jiran tetangga dan sanak saudara terdekat diundang untuk turut membantu menguruskan majlis. Majlis perkahwinan bukan sahaja berfungsi untuk menghebahkan pernikahan pasangan terlibat, bahkan juga untuk mengeratkan silaturrahim dan penyatuan dalam kalangan anggota masyarakat. Dalam Islam, hukum menghadiri atau memenuhi undangan ke majlis perkahwinan adalah fardhu 'ain iaitu wajib ke atas setiap individu yang diundang. Ini berdasarkan kepada sabda Rasulullah SAW yang bermaksud: Apabila salah seorang di antara kamu diundang untuk menghadiri walimah (perkahwinan), maka hendaklah dia datang menghadirinya (Hadis riwayat Bukhari dan Muslim). Lazimnya, undangan ke majlis perkahwinan diterima daripada mereka yang dikenali seperti jiran tetangga, sanak saudara, sahabat handai dan kenalan rapat, yang jika tidak dipenuhi, boleh menyebabkan tercetusnya pelbagai konflik seperti konflik 
kejiranan, kekeluargaan dan juga konflik persahabatan. Sehubungan itu, penulisan ini akan memerihalkan bentuk-bentuk kesantunan linguistik yang diamalkan oleh masyarakat Melayu dalam lakuan bahasa penolakan terhadap undangan ke majlis perkahwinan. Persoalanpersoalan yang akan cuba dirungkai dalam penulisan ini ialah; Bagaimanakah secara linguistiknya orang Melayu memelihara air muka pendengar atau orang yang dilawan bercakap ketika menolak undangan bertuntutan tinggi seperti majlis perkahwinan? Apakah perkataan-perkataan atau ekspresi-ekspresi yang digunakan? Bagaimanakah ia distrukturkan?

\section{Teori Kesantunan Brown dan Levinson $(1978,1987)$}

Kesantunan linguistik merujuk kepada penggunaan bahasa yang berhemah, sopan dan menyenangkan bertujuan untuk menjaga air muka dan mengelakkan pendengar daripada tersinggung atau terasa hati. Menurut Lackoff (1975) kesantunan ialah perlakuan yang dapat mengurangkan pergeseran dalam sesuatu interaksi. Fraser dan Nolan (1981) pula menegaskan bahawa kesantunan berlaku apabila kontrak perbualan digunakan oleh penutur dan pendengar sebagai usaha untuk mengekalkan komunikasi yang harmoni tanpa menimbulkan sebarang konflik. Leech (1983) mentakrifkan kesantunan sebagai perlakuan yang mewujudkan dan mengekalkan pengiktirafan diri dalam sesuatu interaksi sosial. Manakala Brown dan Levinson (1987) merujuk kesantunan sebagai usaha untuk mengurangkan ancaman terhadap air muka pendengar.

Teori Kesantunan yang telah diperkenalkan oleh Brown dan Levinson (1978) telah mencetuskan fenomena dalam kajian pragmatik khususnya kajian berkaitan lakuan bahasa. Bermula daripada konsep "muka" (face) yang dicetuskan oleh Goffman (1967), Brown dan Levinson mengatakan bahawa dalam interaksi seharihari manusia mempunyai "air muka" yang harus dipelihara. Menurut Brown dan Levinson, kesantunan berfungsi sebagai penyelamat air muka dan merupakan "satu bentuk kawalan emosi yang berperanan sebagai alat untuk memelihara air muka".

Seterusnya Brown dan Levinson menegaskan bahawa setiap individu normal terikat dengan dua jenis kehendak air muka, iaitu air muka positif dan air muka negatif. Air muka positif merujuk kepada kehendak untuk dipandang mulia serta dihargai oleh orang lain. Ia berkait dengan keinginan untuk memuaskan kehendak ahli dalam kumpulan sosial tertentu. Manakala air muka negatif ditafsirkan sebagai kehendak untuk dibiarkan bebas atau tidak dipaksa melakukan sesuatu atau kehendak untuk mengekalkan kebebasan dalam bertingkah laku. Sama ada penutur maupun pendengar akan saling menjaga air muka positif dan negatif masing-masing dan juga antara satu sama lain. Hal ini terjadi demikian disebabkan oleh kehendak air muka masing-masing untuk tidak dilihat terjejas, seterusnya merosakkan hubungan peribadi di antara keduanya. Sebagai solusi, strategistrategi kesantunan linguistik tertentu digunakan sebagai alat untuk memelihara air muka.

Kebanyakan lakuan bahasa, secara semula jadinya bersifat bertentangan dengan kehendak air muka pendengar atau penutur. Lakuan bahasa tersebut dinamakan Brown dan Levinson sebagai lakuan yang mengancam air muka (Face Threatening Acts). Ia berlaku apabila penutur mengancam air muka positif pendengar dengan menentang kehendak air muka mereka untuk dipandang mulia dan dihargai. Contohnya memaki, mengkritik, menolak dan lain-lain lagi atau penutur mengancam air muka negatif pendengar dengan menentang kebebasan mereka untuk bertindak. Contohnya membuat cadangan, menasihati, mengemukakan permintaan, 
mendesak dan lain-lain lagi. Membuat aduan, menyampuk dan lain-lain pula ialah lakuan bahasa yang boleh mengancam kehendak kedua-dua air muka, positif dan negatif.

Kadangkala, penutur tidak dapat mengelak daripada menjejaskan air muka pendengar ketika melaksanakan sesuatu lakuan bahasa. Oleh demikian, sebelum mengujarkan sesuatu, penutur harus menimbangkan dahulu potensi ujarannya sama ada akan mengancam air muka atau tidak. Dalam hal ini, Brown dan Levinson telah mencadangkan strategi-strategi utama untuk melaksanakan lakuan bahasa yang mengancam air muka, iaitu laksanakan lakuan yang mengancam air muka atau tidak laksanakannya. Jika memilih untuk melaksanakannya, ia boleh dilakukan secara langsung atau tidak langsung. Lakuan secara langsung pula terbahagi kepada dua iaitu secara mengendurkan ancaman atau tanpa pengenduran ancaman. Seterusnya, pengenduran ancaman mempunyai dua pecahan iaitu kesantunan positif dan negatif.

Menurut Brown dan Levinson, seseorang itu boleh memilih untuk melakukan lakuan bahasa yang mengancam air muka atau tidak melakukannya. Jika mereka memilih untuk tidak melakukannya, bermakna lakuan bahasa tersebut berada di tahap ancaman air muka yang tinggi. Semakin tinggi ancaman, semakin rendah darjah kelangsungan strategi. Sebaliknya, semakin rendah ancaman, semakin tinggi pula darjah kelangsungannya. Contohnya penolakan, yang memang terkenal dengan sifatnya yang sukar dan sangat mengancam air muka. Untuk melaksanakannya mungkin penutur akan memilih strategi tidak langsung. Untuk melaksanakan lakuan bahasa yang lain, contohnya memuji yang tidak bersifat mengancam air muka, mungkin penutur akan memilih strategi langsung. Seorang penutur harus menimbangkan dahulu potensi ancaman air muka oleh lakuan bahasa yang akan digunakannya sebelum memilih strategi yang sesuai untuk meminimumkan kesan ancaman tersebut. Di samping itu, menurut Brown dan Levinson, pelbagai faktor lain seperti status dan jarak sosial serta darjah imposisi lakuan bahasa turut mempengaruhi pemilihan strategi. Malah tahap keseriusan sesuatu lakuan bahasa itu ditentukan oleh ketiga-tiga faktor di atas seperti yang diformulakan oleh Brown dan Levinson sebagai berikut; $\mathrm{W}=\mathrm{P}(\mathrm{H}, \mathrm{S})+\mathrm{D}(\mathrm{H}, \mathrm{S})+$ R. Namun, dalam artikel ini, penulis hanya memfokuskan perbincangan kepada strategi dan struktur yang digunakan dalam konteks undangan perkahwinan tanpa melihat kepada sebarang pemboleh ubah tersebut.

\section{Metodologi}

40 orang responden Melayu berusia dalam lingkungan 30 hingga 40 tahun terlibat dalam kajian ini. Instrumen yang digunakan untuk mengumpul data ialah satu set kertas soal selidik berbentuk Tugas Penyempurnaan Wacana (Discourse Completion Test) dalam bahasa Melayu. Discourse Completion Test atau ringkasannya $D C T$ ialah kertas soal selidik yang mengandungi situasi yang memerlukan responden melaksanakan lakuan bahasa yang dikehendaki dengan membayangkan diri mereka benar-benar berada di dalam situasi yang diberi. $D C T$ telah diperkenalkan oleh Blum-Kulka(1982) dan telah digunakan dengan meluasnya dalam kajian-kajian yang melibatkan lakuan bahasa. Data dianalisis menggunakan model penolakan Beebe, et al. (1990). Unit yang dianalisis ialah kenyataan yang ditulis oleh responden sebagai respon ke atas situasi yang diutarakan dalam kertas soal selidik. Contohnya, jika responden menolak dengan berkata "Maaf saya tak dapat hadir, saya ada urusan nak diselesaikan" akan dianalisis sebagai "Ungkapan maaf", "Ungkapan ketidaksediaan/ketidakmampuan" dan "Alasan". Dalam kes di mana responden menolak dengan menulis "Terima kasih. Tapi saya tak dapat pergi. Saya ada temu janji dengan seseorang”, akan dianalisis 
sebagai "Penghargaan", "Ungkapan ketidaksediaan/ketidakmampuan" dan "Alasan".

\section{Dapatan Kajian}

Analisis data dibahagikan kepada dua bahagian iaitu analisis strategi penolakan dan analisis struktur penolakan.

\section{Analisis Strategi Penolakan}

Kebanyakan responden memilih untuk menolak menggunakan strategi tidak langsung. $\quad 10$ strategi berbeza yang ditemui dalam data penolakan responden ialah strategi "Ungkapan ketidaksediaan/ ketidakmampuan", "Ungkapan maaf", "Ungkapan harapan/keinginan", "Alasan", "Syarat penerimaan di masa hadapan", "Ancaman atau akibat yang negatif", "Ungkapan menenangkan", "Ungkapan positif", "Pengisian jeda" dan "Penghargaan".

\section{Ungkapan Ketidakmampuan}

Ketidaksediaan/

Strategi penolakan ini mencatat kekerapan penggunaan sebanyak 24 kali (20\%) dalam kalangan responden. "Ungkapan ketidaksediaan/ketidakmampuan" merujuk kepada penolakan yang menggunakan katakata seperti, "saya tidak boleh", "saya tidak mahu", "saya tidak mampu", "saya tidak akan" dan sebagainya yang mengandungi unsur penafian terhadap sesuatu cadangan atau usulan yang terdapat dalam sesuatu permintaan, tawaran atau undangan. Contohnya responden berkata "Saya tidak boleh pergi ke majlis tu" atau "Saya tidak akan hadir ke majlis tu" dan lain-lain lagi.

\section{Ungkapan Maaf}

Strategi ini mencatat kekerapan penggunaan sebanyak 32 kali (26\%) dalam kalangan responden. Ia merupakan kata- kata permohonan maaf seperti "maafkan saya", "saya minta maaf", "maaflah ya", "maaf" atau "ampun" yang digunakan untuk menzahirkan rasa bersalah atau kecewa responden kerana terpaksa menolak permintaan, cadangan atau undangan interlokutor. Contohnya, "saya minta maaf, saya tak dapat hadir ke majlis awak" atau "maafya, saya tak boleh pergi ke majlis tu" dan lain-lain lagi.

\section{Ungkapan Harapan/Keinginan}

Kekerapan penggunaan strategi ini dalam kalangan responden adalah sebanyak 8 kali (6\%). Strategi ini merujuk kepada ekspresi keinginan atau harapan responden untuk memenuhi permintaan, cadangan atau undangan interlokutor. Misalnya, responden mengujarkan "saya berharap sangat saya dapat pergi tapi..." atau "kalaulah saya dapat pergi, tapi..." dan lain-lain lagi.

\section{Alasan}

"Alasan" merupakan strategi yang paling kerap digunakan dalam kalangan responden untuk menolak undangan ke majlis perkahwinan. Strategi ini merekodkan kekerapan sebanyak 32 kali atau 26\%, sama seperti strategi "Ungkapan maaf". Ia merujuk kepada sebab, alasan atau penjelasan sama ada umum maupun spesifik yang diberikan oleh responden untuk menampakkan penolakan mereka itu wajar atau bersebab. Alasan yang umum ialah alasan yang tidak mengandungi butiran yang terperinci seperti, "saya tak dapat pergi kerana saya ada hal" atau "saya tak boleh pergi kerana ada urusan", dan lain-lain lagi. Manakala alasan yang spesifik merujuk kepada alasan yang disertakan dengan perincian seperti "saya tidak dapat pergi kerana saya terpaksa menjaga tiga orang anak kakak saya yang sedang berkursus di luar negara selama sebulan" atau "saya tak boleh pergi ke majlis tu kerana saya telah berjanji dengan suami untuk mengikutnya balik kampung kerana ada kenduri saudaranya di sana", dan lain-lain lagi. 


\section{Syarat Penerimaan di Masa Hadapan}

Strategi ini mencatatkan kekerapan sebanyak 2 kali atau 2\% dalam kalangan responden. Ia merupakan strategi tidak langsung yang digunakan oleh responden untuk menolak undangan atau permintaan dengan membuat ramalan atau hipotesis tentang masa akan datang. Misalnya responden mengatakan "jika kenduri tu bulan depan, saya boleh hadir" atau "kalau tarikh kenduri tu minggu depan, saya tak ada masalah untuk hadir", dan lain-lain lagi.

\section{Ancaman atau Akibat yang Negatif}

Strategi ini hanya digunakan sekali sahaja atau $1 \%$ dalam kalangan responden. Strategi ini merujuk kepada penggunaan kata-kata yang membawa pengertian mengancam atau akan membawa akibat buruk jika permintaan atau undangan berkenaan ditunaikan. Tujuannya adalah untuk meyakinkan interlokutor bahawa penolakannya itu adalah sesuatu yang dilakukan kerana terpaksa, bukannya disengajakan, sekaligus diharapkan akan dapat mengurangkan kekesalan di pihak interlokutor yang mengharapkan permintaan, cadangan atau undangan mereka dipenuhi. Contohnya responden berkata, "saya dah janji dengan mak nak balik kampung, kalau saya pergi ke kenduri tu, nangislah mak tunggu saya" atau "saya ada kursus, kalau saya pergi ke majlis tu, mengamuklah bos saya" dan lain-lain lagi.

\section{Ungkapan Menenangkan}

Strategi ini digunakan oleh responden sebanyak dua kali atau $2 \%$ dalam penolakan mereka. "Ungkapan menenangkan" ialah ungkapan atau kata-kata yang digunakan oleh responden untuk mengurangkan rasa bimbang atau risau interlokutor disebabkan oleh penolakan yang terpaksa dilakukan oleh responden. Misalnya responden mengatakan, "saya tak boleh hadir majlis tu, tapi jangan risau saya doakan segalanya berjalan lancar nanti" atau "saya ada urusan hari tu, jangan bimbanglah, insyaAllah majlis tu akan tetap meriah tanpa saya" dan lain-lain lagi.

\section{Ungkapan Positif}

Strategi ini merekodkan kekerapan penggunaan dalam kalangan responden sebanyak 13 kali atau $11 \%$. Strategi ini merujuk kepada sebarang kata-kata positif berupa tahniah dan sebagainya yang diekspresikan oleh responden untuk mengurangkan ancaman terhadap air mukanya sendiri dan juga air muka interlokutor. Contohnya, "Tahniah ya, tapi maaf saya tak dapat hadir..." atau "Bagusnya, tapi saya tak boleh pergilah, ada urusan" dan lain-lain lagi.

\section{Pengisisan Jeda}

Strategi ini ditemui dalam data penolakan responden sebanyak tiga kali atau $2 \%$. Pengisian jeda merujuk kepada ungkapan tanpa makna yang diujarkan untuk mengisi jeda dalam perbualan seperti, "Hrm...", "Mmm..." atau "erm..." dan lain-lain lagi.

\section{Penghargaan}

Strategi "Penghargaan" ditemui sebanyak 5 kali atau $4 \%$ dalam data penolakan responden. Penghargaan merujuk kepada ungkapan untuk menunjukkan penghormatan, rasa syukur atau berterima kasih kepada orang yang dilawan bercakap. Contohnya, "Terima kasih kerana menjemput saya, ...", "Terima kasih tapi ..." atau "Terima kasih ya, tapi ..." dan lain-lain lagi.

\section{Analisis Struktur Penolakan}

Lapan struktur yang berbeza ditemui dalam data penolakan responden. Bilangan, peratus dan contoh setiap struktur ditunjukkan dalam jadual 2 di sebelah. 


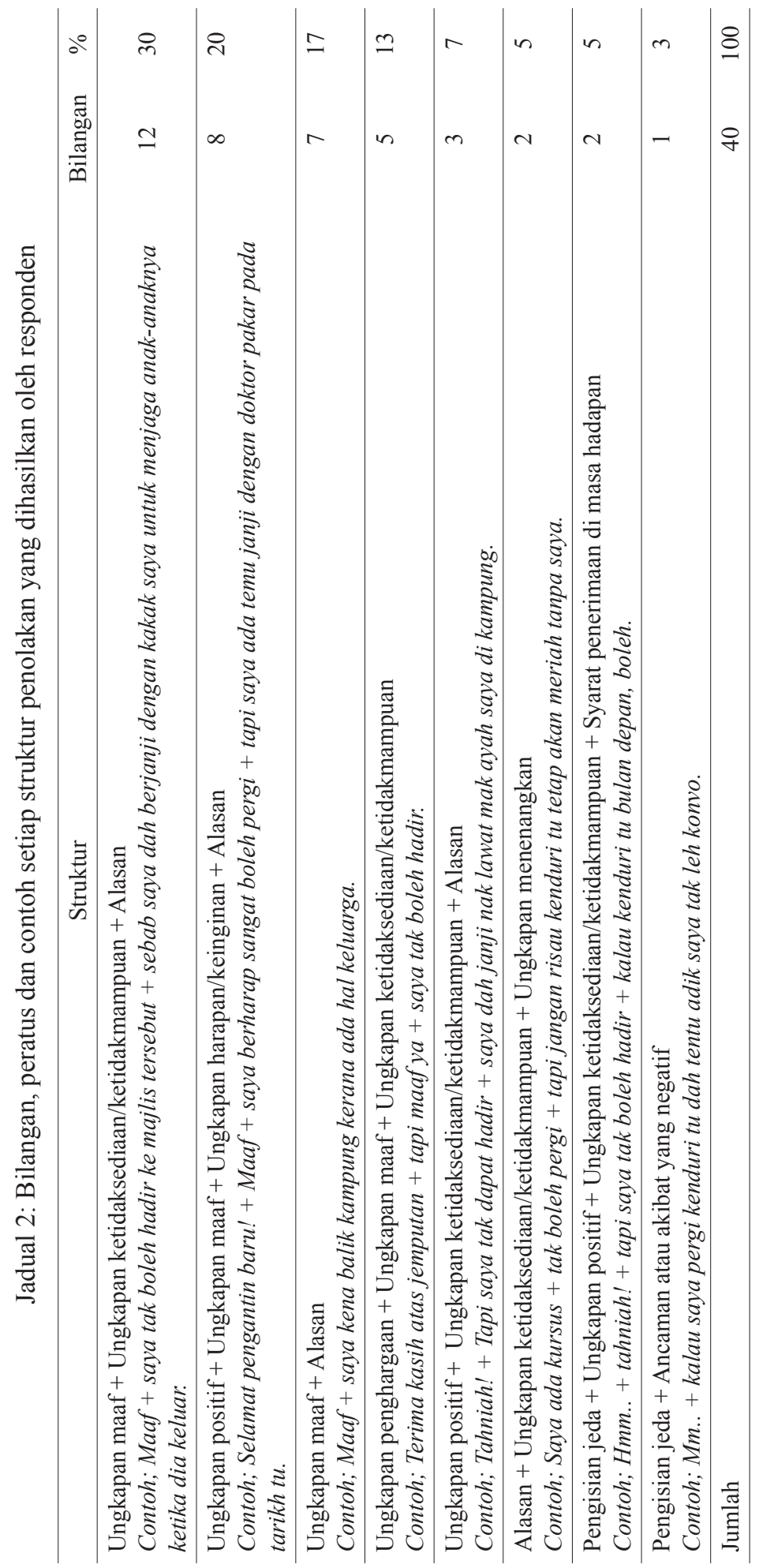


Seperti yang diperhatikan daripada jadual 2 di atas, majoriti iaitu 30\% daripada responden memulakan penolakan mereka dengan ungkapan maaf diikuti oleh ungkapan ketidaksediaan/ketidakmampuan dan alasan. Contohnya, responden menolak dengan berkata "Maaf, saya tak boleh hadir ke majlis tersebut sebab saya dah berjanji dengan kakak saya untuk menjaga anak-anaknya ketika dia keluar", "Maaf, saya tak dapat pergi kerana saya telah diarahkan majikan untuk bertugas di luar kawasan pada tarikh tersebut", "Maaf, tak dapat hadir kerana saya akan pergi bercuti bersama keluarga", "Maafya, saya tak dapat hadir, saya dah janji nak lawat mak ayah saya di kampung" atau "Minta maaf, saya memang tak boleh pergi, suami tak sihat, saya kena jaga dia di rumah" dan lain-lain lagi.

\section{Kesimpulan}

Penggunaan pelbagai strategi tidak langsung dalam penolakan responden menunjukkan yang masyarakat Melayu masih beralas atau berlapik dalam mengujarkan sesuatu. Penolakan, lebih-lebih lagi dalam konteks undangan perkahwinan merupakan satu tindakan yang sukar untuk dilaksanakan oleh orang Melayu. Hal ini mendorong mereka menggunakan pelbagai strategi untuk meminimunkan kebarangkalian menjejaskan air muka interlokutor di samping air muka mereka sendiri. Bagi orang Melayu, menjaga hati orang lain itu lebih penting berbanding menyatakan kehendak diri mereka sendiri. Meskipun terpaksa menolak, namun penolakan mereka tetap beralas dan berlapik dengan pelbagai strategi atau ekspresi tidak langsung untuk mengelakkannya daripada kedengaran terlalu langsung sekaligus menyinggung perasaan pihak lain.

Selain itu, masyarakat Melayu merupakan masyarakat yang mementingkan maruah dan air muka pihak lain ketika berkomunikasi. Ini ditunjukkan oleh struktur penolakan yang dihasilkan oleh responden. Kebanyakan responden memulakan penolakan dengan permohonan maaf diikuti oleh penyataan tidak boleh dan alasan. Masyarakat Melayu menyedari bahawa menolak undangan bertuntutan tinggi seperti undangan perkahwinan merupakan satu tindakan yang amat tidak wajar lalu mendorong mereka memulakan penolakan dengan permohonan maaf. Ia merupakan refleksi rasa bersalah mereka kerana terpaksa menghampakan pihak lain. Di samping untuk memelihara air muka pendengar, permohonan maaf itu juga merupakan satu tindakan untuk menjaga air muka sendiri agar tidak terlihat sebagai seorang yang sombong dan mementingan diri sendiri. Selain itu, permohonan maaf itu juga menunjukkan sikap rendah diri masyarakat Melayu terhadap pihak yang dirasakan telah dikecewakan mereka, kerana kesanggupan memohon maaf lazimnya terbit daripada hati dan jiwa yang murni serta sifat merendah diri.

\section{Penghargaan}

Penulis ingin merakamkan ucapan terima kasih kepada Prof. Dr. Emilio Ridruejo atas bimbingan yang telah diberikan kepada penulis dalam menyiapkan kajian berkaitan. Makalah ini merupakan sebahagian daripada dapatan yang diperolehi daripada kajian $\mathrm{PhD}$ yang telah dijalankan oleh penulis di bawah penyeliaan beliau di Universidad de Valladolid, Sepanyol. Penulis juga ingin merakamkan ucapan penghargaan terhadap pihak KPTM dan UMT atas tajaan pengajian tersebut.

\section{Rujukan}

Allami, H., \& Naeimi, A. (2011). A crosslinguistic study of refusals: An analysis of pragmatic competence development in Iranian EFL learners. Journal of Pragmatics, 43(1), 385-406. 
Al-Eryani, A. (2007). Refusal strategies by Yemeni EFL learners. The Asian EFL Journal, 9 (2), 19-34.

Al-Issa, A. (1998). Sociopragmatic transfer in the performance of refusals by Jordanian EFL learners: Evidence and motivating factors. Unpublished Doctoral Dissertation, Indiana: Indiana University of Pennsylvania.

Al-Shalawi, H. (1997). Refusal strategies in Saudi and American cultures. Unpublished Master's Thesis, Michigan: Michigan State University.

Beckers, A., M. (1999). How to Say "No" wihout Saying "No". A study of the refusal strategies of Americans and Germans. Unpublished Doctoral Dissertation, The University of Mississippi, Mississippi.

Beebe, L., Takahashi, T., \& UlissWeltz, R. (1990). Pragmatic transfer in ESL refusals. Dalam, R. et al. (eds.), Developing Communicative Competence in a Second Language (pp. 55-73). New York: Newbury House.

Blum-Kulka, S. (1982). Learning to say what you mean in a second language: a study of the speech act performance of learners of Hebrew as a second language. Applied Linguistics, 3, 2959.

Brown, Penelope \& Stephen C. Levinson. (1987 [1978]). Politeness. Some universals in language usage. Cambridge: Cambridge University Press.

Devito, Joseph A. (2009). The interpersonal communication book. (12th ed.) Boston, New York: Pearson International Edition.

Félix-Brasdefer, J. César. (2002). Refusals in Spanish and English: A crosscultural study of politeness strategies among speakers of Mexican Spanish,
American English, and American learners of Spanish as a foreign language. Tesis Doctoral, Minnesota: University of Minnesota.

Goffman, E. ([1967] 1982). On face-work. An analysis of ritual elements in social interaction. Interactional ritual. Essays on face to face behaviour, New York: Anchor Books, 5-45.

Grice, H. Paul. (1989). Studies in the way of words. Cambridge: Harvard University Press.

Lakoff, Robin T. (1973). The logic of politeness; or minding your p's and q's. Dalam Papers from the seventh regional meeting of the Chicago Linguistic Society (pp. 292-305). Chicago: Chicago University Press.

Leech, N. Geoffrey. (1983). Principles of pragmatics. Londres: Longman.

Liao, C., \& Bresnahan, M. I. (1996). A comparative pragmatic study on American English and Mandarin refusal strategies. Language Sciences, $18,703-727$.

Lyuh, I. (1992). The Art of Refusal: Comparison of American and Korean Cultures. Unpublished Doctoral Dissertation, Indiana University.

Norma, S., Siti Jamilah, B., \& Ahmad Affendi, S. (2016). Refusal strategies used by malay esl students and english native speakers to refuse a request. Proceeding of ICECRS, 1-11.

Nelson, G., Carson, J., Al Batal, M., \& El Bakary, W. (2002). Cross-cultural pragmatics: strategy use in Egyptian Arabic and American English refusals. Applied Linguistics 23 (2), 163-189.

NorAzuwan, Y, Norazlina, M. K., Kamariah, K., \& Zaitul Azma Zainon, H, (2011). Kesantunan berbahasa dalam aktiviti program Latihan Khidmat Negara (PLKN). Journal of Human Capital Development, 4(1), 53-55. 
Rubin, Joan. (1983). How to tell when someone is saying 'no' revisited. In N. Wolfson \& E. Judd, (Eds.). Sociolinguistics and language acquisition (pp. 10-17). Rowley, MA: Newbury House.

Yusniza, Y., Faizah, A., \& Nasariah, M. (2011). Kesantunan bahasa dalam kalangan pelajar ipt: satu kajian perbandingan ethik. Dlm. Abdul Rahman Aziz \& Mohd Azizuddin Mohd Sani (Eds.). Agenda Ketahanan Nasional Malaysia. Universiti Utara Malaysia: Institut Pemikiran Tun Dr. Mahathir.
Zaitul Azma Zainon, H. (2012). Kesantunan dan strategi berbahasa dalam konteks pendidikan. Dlm Marlyna Maros et al. (Eds.). Kesantunan berbahasa, (hlm. 63-81). Kuala Lumpur: Dewan Bahasa dan Pustaka.

Zulkifley, H., \& Naidatul, Z. A (2013). Memupuk perpaduan di Malaysia Santun bahasa dalam kalangan murid pelbagai etnik dari aspek penggunaan kata ganti nama diri. GEOGRAFIA OnlineTM Malaysian Journal of Society and Space, 9(4), 86-98.

Zuraini, R., Dahlia, J., Husna Faredza, M. R., \& Khairul Azam, Bahari (2009). Amalan kesantunan berbahasa di sekolah. Project Report. Universiti Pendidikan Sultan Idris. 


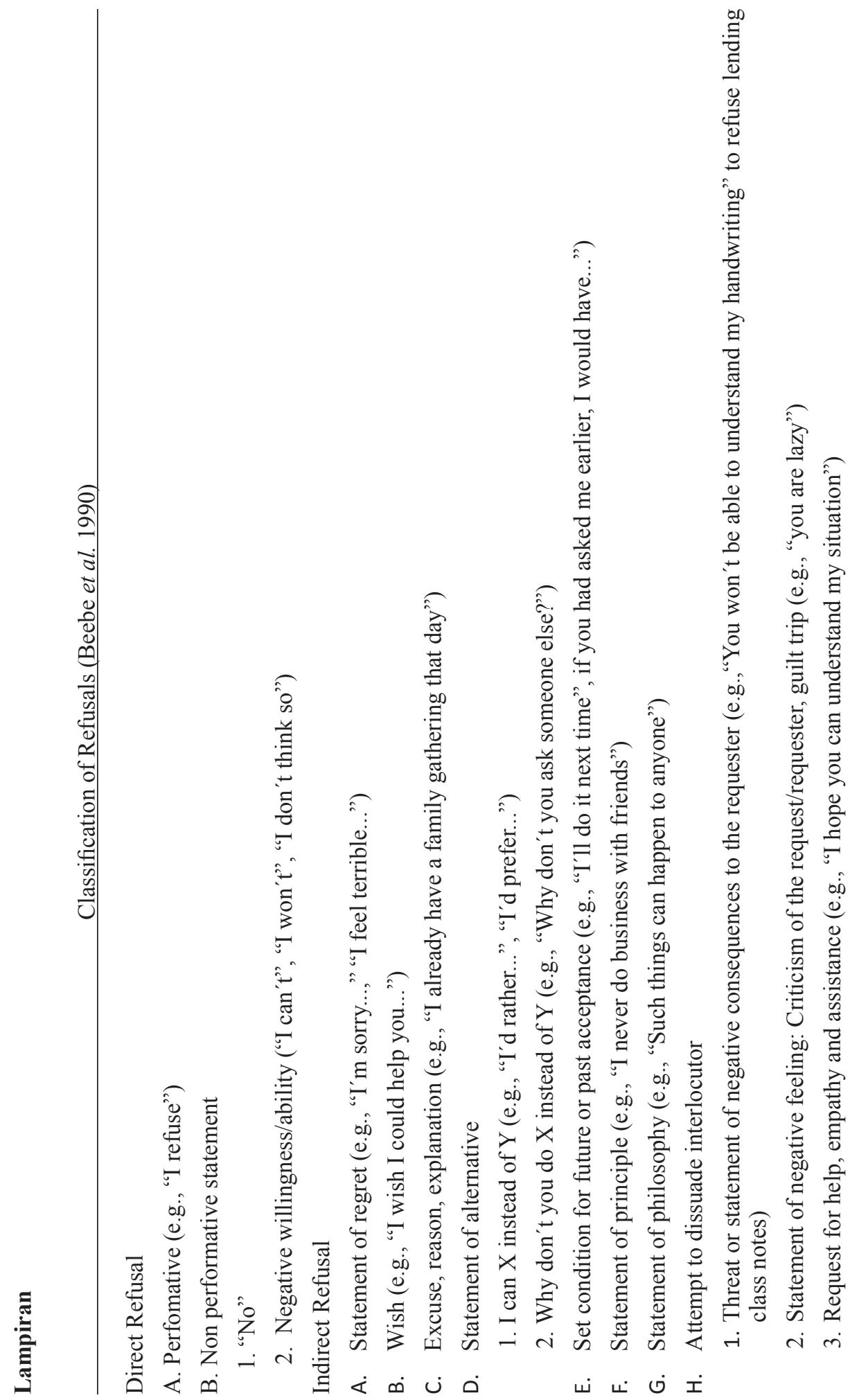




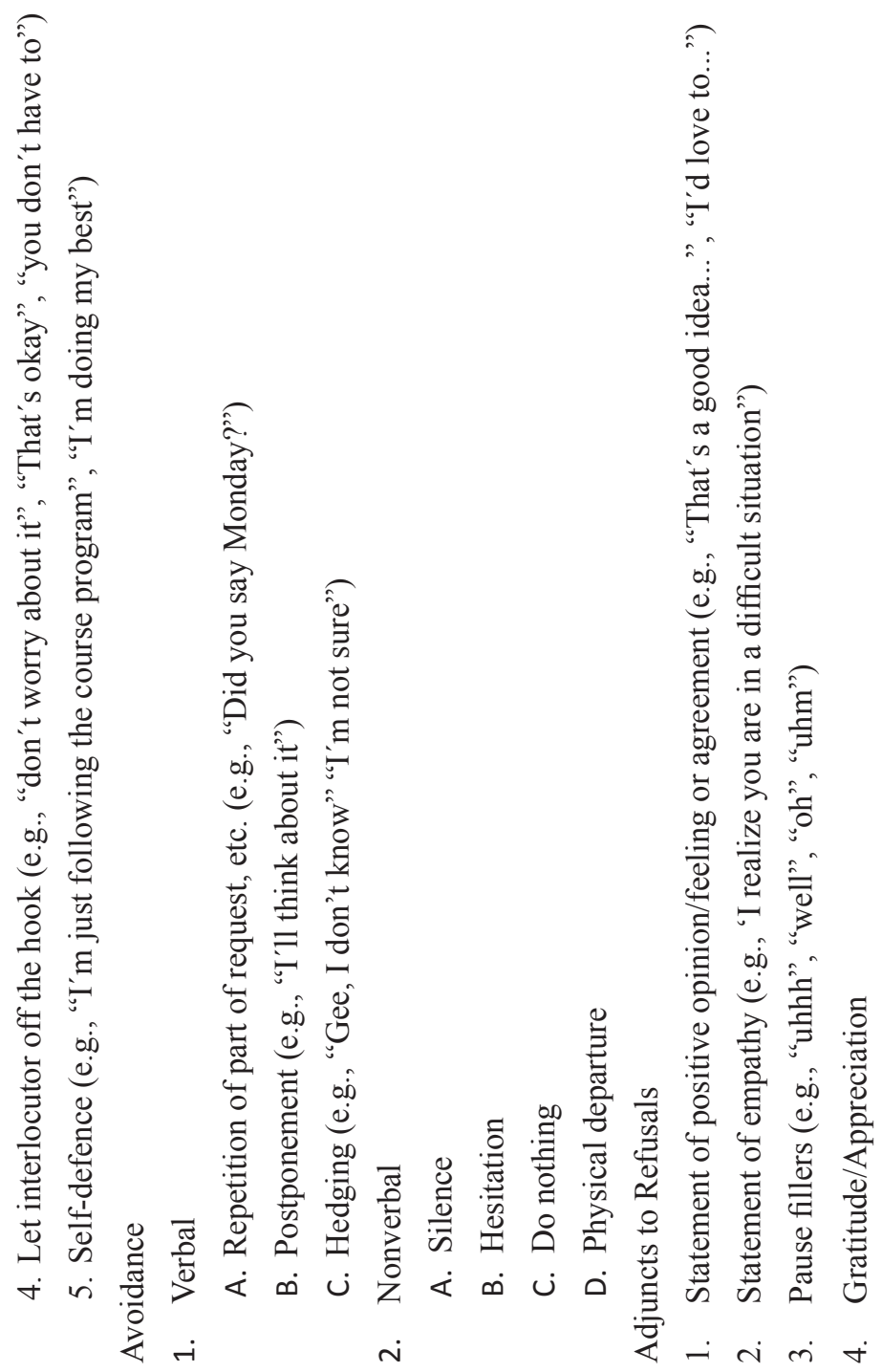

Journal of Business and Social Development Volume 8 Number 2, September 2020 : 65-76 